\title{
Presence of an articulating condylus tertius on the basilar part of the occipital bone- $\mathrm{A}$ rare anatomical abnormality
}

\author{
Vinod Kumar $\left({ }^{*}\right)$, Ashutosh S Rao $\left(^{* *}\right)$, Mohandas Rao KG $\left(^{* * *}\right)$, Jyothsna P $\left(^{* * *}\right)$, Ashwini LS $\left({ }^{* * *}\right)$, \\ Sapna $M\left({ }^{* * *}\right)$
}

\begin{abstract}
Normally, in human skulls, the basilar part of the occipital bone presents two occipital condyles which articulate with the superior articular facets of the atlas vertebra. A rare case of third occipital condyle (condylus tertitus) with an additional articular facet on it was observed in a dry skull from South India. The third condyle was on the basilar part of the occipital bone along the anterior margin of the foramen magnum. It showed an additional articular facet which was smooth surfaced and oval in shape measuring $1 \mathrm{~cm}$ antero-posteriorly and $1.5 \mathrm{~cm}$ transversely at its maximum width. Available literature on the condylus tertius and its clinical, surgical and radiological importance were discussed.
\end{abstract}

Key words: Condylus tertius, occipital bone, atlantooccipital joint, atlas vertebra, axis vertebra
* Department of Anatomy, Sapthagiri Institute of Medical Sciences and Research Centre, Hesarghatta Main Road, Bangalore

** Department of Orthopedics, Faculty of Medicine, AIMST University, Semeling, Bedong- 08100, Kedah, Malaysia

*** Department of Anatomy, Melaka Manipal Medical College (Manipal Campus), Manipal University, Manipal 576 104, India

Reprint request: Dr. Mohandas Rao K. G., Associate Professor of Anatomy Melaka Manipal Medical College (Manipal Campus) Manipal University, Manipal 576104

E-mail: mohandaskg@gmail.com

Date submitted: December 16, 2011 Date accepted: January 09, 2012 Online publication date: September 26, 2013

\section{Introduction:}

Normally, in human skulls, the basilar part of the occipital bone presents two occipital condyles which articulate with the superior articular facets of the atlas vertebra. Both articular surfaces are reciprocally curved and form ellipsoid joints [1]. These joints normally permit biaxial movements, forward (flexion) and backward (extension) nodding of (skull) head at a transverse axis which has total range of $15^{\circ}$ and right and left lateral flexion of the head (skull) at an anteroposterior axis [1]. In addition to normal occipital condyles, a third occipital condyle with an additional articular facet on it was observed on the basilar part of the occipital bone along the anterior margin of the foramen magnum in a dry human skull.

\section{Case report}

In one of the dry human skulls used for osteology demonstration sessions, a rare feature was observed on the norma basalis. The abnormal skull belonged to an adult person from South India whose age and sex are not known. The skull showed a third condyle (condyles tertius) on the basilar part of the occipital bone along the anterior margin of the foramen magnum. This $3^{\text {rd }}$ condyle was broader when compared to the normal occipital condyles and was having an articular facet on its inferior surface. The articular facet was smooth surfaced and oval in shape measuring $1 \mathrm{~cm}$ anteroposteriorly and $1.5 \mathrm{~cm}$ transversely at its maximum width (Figure 1 and Figure 2).

\section{Discussion}

The condylus tertius was first described by Meckel JF in 1815 [2]. It is a bony process on the anterior 
surface of the clivus (front rim of the occipital foramen magnum). The condylus tertius may be tightly attached or present as an isolated bone element. It may also be articulated with the tip of dens of the axis or with the anterior atlantic arch. The condylus tertius is regarded as a rare variation [3]. Various authors have quoted an incidence of tertiary condyle on the skull between $0.25 \%$ and $1 \%$ [2]. Functional impairment with the presence of this bony process

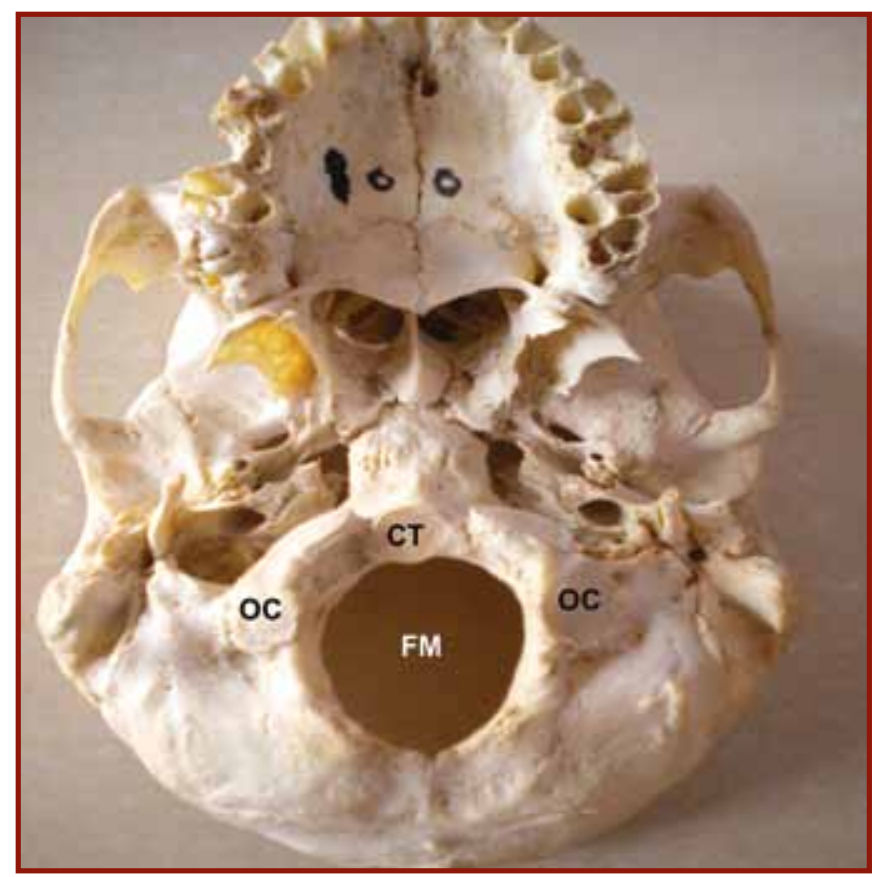

Figure 1. Picture of the norma basalis of the human skull showing the articular condylus tertius (CT) along the anterior margin of the foramen magnum (FM). Normal bilateral occipital condyles (OC) are also seen.

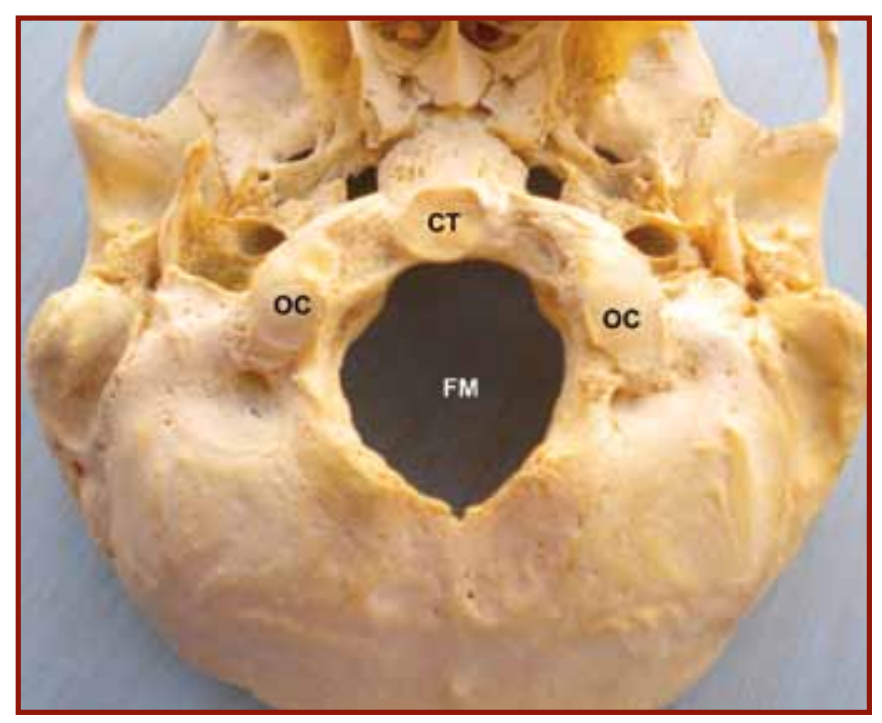

Figure 2. Picture of the norma basalis of the human skull showing the closer view of the articular condylus tertius (CT) along the anterior margin of the foramen magnum (FM). Normal bilateral occipital condyles $(\mathrm{OC})$ are also seen. was demonstrated with a 3 point contact between the skull base and the upper cervical vertebrae [3]. Saternus et al., proposed a constitutional genesis to the formation of this bony processes. They opined that its position varies over the anterior arch of the atlas and the apex of the dens as a result of rotatory forces between the atlas and axis and physiological strain [3]. v Lüdinghausen et al., described the condylus tertius to be articulating in two facets with the dens of axis and the anterior arch of the atlas, forming the (normal) median atlantoaxial joint [4]. However, in the present case, the condylus tertius presented only one articular surface.

Occurrence of the condyles tertius is considered as one of the rare congenital abnormalities [5]. Embryologically, the components of the central pillar (body and the dens of the axis) are derived from the axial portion of the occipital and upper two cervical sclerotomes. The ring structures (lateral mass and arch of atlas) are derived from the lateral portion of the same sclerotomes and a small sclerotomal off-shoot ventral to the notochord called the hypochordal bow of proatlas [6]. Condylus tertius is an expression of the hyperplasia of hypochordal bow of proatlas resulting from lack of fusion of the lowermost $4^{\text {th }}$ sclerotome (proatlas) with the adjacent portion of the clivus [3].

\section{Clinical Importance}

Prescher et al., have attributed different anatomic appearance of the condyle to various degrees of persistence and the finding of an articulated condylus tertius to be the highest degree of persistence [2]. Variations in the craniovertebral junction (CVJ) may be asymptomatic [2]. However, they are of interest to the clinicians as they can produce clinical symptoms [7]. Clinical manifestations develop only with advanced age or after a traumatic event [2]. Common symptoms of pain and vertigo can be produced by instability, compression of neurological or vascular structures or due to mechanical derangements like additional articulations. Presence of an articulation between the two would expose it to the various pathologies attributed to a joint. They can undergo degenerative changes and present with arthrosis of the joint $[4,7]$. The three point contact of the condylus tertius presents with restriction of movements of the neck and also can become a bony cause for torticollis of the neck [2]. Symptoms of these presentations should be carefully assessed and differentiated 
from some conditions that can mimic them like syringomyelia, multiple sclerosis, and amyotrophic lateral sclerosis cause similar symptoms [2].

Radiological diagnosis of these anomalies is difficult and goes undetected due to lack of experience in identification due to rarity. It would require a high degree of suspicion and careful analysis of the radiology as also more investigations to make a diagnosis. Several radiological lines and angles are used in the diagnosis of condyles tertius. Many of these abnormal processes have been diagnosed to be tumors. The condylus tertius, radiologically, is seen as a small, or bulky, large bony element, attached to the anterior margin of the basiocciput or unattached between the occipital bone and the anterior arch of the atlas or the tip of the dens of axis [4]. A median placed condylus tertius has to be differentiated from an ossification of the apicis dentis ligament and a false condylus tertius. Tomography and CT scans have been useful in its diagnosis [2]. The third condyle can be differentiated from the ossiculum terminale and the os-odontoideum as it is not associated with hypoplasia of the dens [2].

Many medical and surgical disciplines are involved in the management of lesions in the craniovertebral junctions and hence abnormalities in this area and variations thereof must be known for proper diagnosis and management. Some of these lesions are confused to more sinister conditions like tumors and others make surgical procedures more difficult by their presence [2].

To conclude, occurrence of the condyles tertius in human skull is a very rare abnormality. The knowledge of such variation is useful for the clinicians, surgeons and radiologists.

\section{Consent}

Written informed consent could not be obtained from the subject's relatives as the origin of the skull was not known. However, an approval from the institutional ethical committee has been obtained for the publication of this case report.

Competing interests: No competing interests

\section{Authors' contributions}

Vinay Kumar discovered the variation. He also obtained written consent from the other authors.

Ashutosh S Rao gave input on the clinical and surgical importance of the case.

Mohandas Rao KG, Jyothsna, Ashwini, Sapna wrote the case report and drafted the manuscript. They were also involved in the literature search.

\section{References}

1. Standring S, Borley NR, Collins P, Crossman AR, Gatzoulis MA, Healy JC et al. Gray's Anatomy: The Anatomical Basis of Clinical Practice. 40th Edition, Elsevier, Churchill Liwingstone, London. 2008; 733-4.

2. Prescher A, Brors D, Adam G. Anatomic and Radiologic Appearance of Several Variants of the Craniovertebral Junction. Skull Base Surgery 1996; 6: 83-94

3. Saternus KS, Kernbach-Wighton G, Koebke J. The mobile Condylus tertius occipitalis and fractures of the hypochordal clasp. Anthropol Anz 2008; 66:155-165.

4. v Lüdinghausen M, Schindler G, Kageyama I, Pomaroli A. The third occipital condyle, a constituent part of a median occipito-atlanto-odontoid joint: a case report. Surg Radiol Anat 2002; 24:71-76.

5. Smoker WR. Craniovertebral junction: normal anatomy, craniometry, and congenital anomalies. Radiographics 1994; 14: 255-277.

6. Pang D, Thompson DN. Embryology and bony malformations of the craniovertebral junction. Childs Nerv Syst 2011; 27:523-564.

7. Rao PV. Median (third) occipital condyle. Clin Anat 2002; 15:148-151. 